\title{
UCRL-JRNL-218199
}

LAWRENCE LIVERMORE N A T IO N A L LABORATORY
Investigating Uranium Isotopic Distributions in Environmental Samples Using AMS and MC-ICPMS

B. A. Buchholz, T. A. Brown, T. F. Hamilton, I. D. Hutcheon, A. A. Marchetti, R. E. Martinelli, E. C. Ramon, S. J. Tumey, R. W. Williams

January 17, 2006

Nuclear Instruments and Methods B 
This document was prepared as an account of work sponsored by an agency of the United States Government. Neither the United States Government nor the University of California nor any of their employees, makes any warranty, express or implied, or assumes any legal liability or responsibility for the accuracy, completeness, or usefulness of any information, apparatus, product, or process disclosed, or represents that its use would not infringe privately owned rights. Reference herein to any specific commercial product, process, or service by trade name, trademark, manufacturer, or otherwise, does not necessarily constitute or imply its endorsement, recommendation, or favoring by the United States Government or the University of California. The views and opinions of authors expressed herein do not necessarily state or reflect those of the United States Government or the University of California, and shall not be used for advertising or product endorsement purposes. 
Investigating uranium isotopic distributions in environmental samples using AMS and MC-ICPMS.

B.A. Buchholz, T.A. Brown, T.F. Hamilton, I.D. Hutcheon, A.A. Marchetti, R.E. Martinelli, E.C. Ramon, S.J. Tumey, R.W. Williams

Presentation \# P1-D7

Contact Author:

B. A. Buchholz

CAMS, L397

LLNL

P.O. Box 808

Livermore, CA 94551

USA

Buchholz2@1ln1.gov

925-422-1739(V)

925-423-7884 (FAX)

Presented at 10th International Conference on Accelerator Mass Spectrometry Berkeley, CA

September 5-10, 2005 
Investigating uranium isotopic distributions in environmental samples using AMS and MC-ICPMS.

B.A. Buchholz, T.A. Brown, T.F. Hamilton, I.D. Hutcheon, A.A. Marchetti, R.E. Martinelli, E.C. Ramon, S.J. Tumey, R.W. Williams

\begin{abstract}
Major, minor, and trace uranium isotopes were measured at Lawrence Livermore National Laboratory in environmentally acquired samples using different instruments to span large variations in concentrations. Multi-collector inductively-coupled plasma mass spectrometry (MC-ICPMS) can be used to measure major and minor isotopes: ${ }^{238} \mathrm{U},{ }^{235} \mathrm{U}$, ${ }^{234} \mathrm{U}$ and ${ }^{236} \mathrm{U}$. Accelerator mass spectrometry (AMS) can be used to measure minor and trace isotopes: ${ }^{234} \mathrm{U},{ }^{236} \mathrm{U}$, and ${ }^{233} \mathrm{U}$. The main limit of quantification for minor or trace uranium isotopes is the abundance sensitivity of the measurement technique; i.e., the ability to measure a minor or trace isotope of mass $M$ in the presence of a major isotope at $\mathrm{M} \pm 1$ mass units. The abundance sensitivity for ${ }^{236} \mathrm{U} /{ }^{235} \mathrm{U}$ isotope ratio measurements using MC-ICPMS is around $\sim 2 \times 10^{-6}$. This compares with a ${ }^{236} \mathrm{U} /{ }^{235} \mathrm{U}$ abundance sensitivity of $\sim 1 \times 10^{-7}$ for the current AMS system, with the expectation of 2-3 orders of magnitude improvement in sensitivity with the addition of another high energy filter. Comparing ${ }^{236} \mathrm{U} /{ }^{234} \mathrm{U}$ from MC-ICPMS and AMS produced agreement within $\sim 10 \%$ for samples at ${ }^{236} \mathrm{U}$ levels high enough to be measurable by both techniques.
\end{abstract}




\subsection{Introduction}

Before the development of mass spectrometry techniques uranium isotopes were detected and quantified using $\alpha$-particle spectroscopy. Samples were dissolved in acid, the uranium was chemically purified and concentrated, and the uranium was plated onto a counting planchette. Sample size was constrained to prevent self-shielding and sensitivity was often limited by counting time. Rare isotopes with long half-lives were difficult to detect by decay counting. Many health physics and environmental monitoring labs continue to use $\alpha$-particle spectroscopy today since techniques are well established, sampling processing is relatively simple, and regulations regarding exposures and releases are in terms of $\alpha$-activity.

The history of mass spectrometry applied to uranium goes back at least to experiments carried out by Nier in the early 1940s. Nier produced U+ ions by electron bombardment of $\mathrm{UBr}_{4}$ and measured the abundance of ${ }^{235} \mathrm{U}$ and ${ }^{234} \mathrm{U}[1]$. Shortly thereafter, calutrons were used at Oak Ridge to produce ${ }^{235} \mathrm{U}$ for the US atomic bomb program during WWII. High precision measurements (better than 0.1\%) go back at least to the late 1950s [2]. The development of mass spectrometry analysis techniques significantly improved quantitation for long-lived (semi-stable) isotopes [3-8]. In alpha spectroscopy, detection efficiency is ultimately determined by the ability to retain uranium during the chemical separation and the detector geometry. The chemical form of the uranium on the planchette is not that important as long as the sample is plated thinly. In mass spectrometry, ion source efficiency is generally the limiting factor. Sample matrix and chemical form can dramatically affect ionization efficiency. The formation of hydrides 
in positive ion sources (TIMS, ICPMS) can cause interferences with M-1 isotopes, e.g., ${ }^{235} \mathrm{UH}^{+}$and ${ }^{236} \mathrm{U}^{+}$. AMS initially produces negative ions $\left({ }^{236} \mathrm{U}^{16} \mathrm{O}^{-},{ }^{235} \mathrm{U}^{16} \mathrm{OH}^{-}\right.$and ${ }^{235} \mathrm{U}^{17} \mathrm{O}^{-}$) that are subsequently destroyed in the high energy collision cell that strips electrons to produce a positive charge state. The charge state selected varies among AMS systems and depends upon the charge state distribution and beam transport limitations at each facility. The first ${ }^{236} \mathrm{U}$ AMS measurements were reported by Zhao, et al. (1994) [9], who analyzed Canadian uranium ores. Since then several AMS facilities have pursued ${ }^{236} \mathrm{U}$ measurements [10-16]. To date, the lowest reported ${ }^{236} \mathrm{U} /{ }^{238} \mathrm{U}$ ratios $\left(\sim 10^{-12}\right)$ were recorded in mountain spring water samples [17].

${ }^{236} \mathrm{U}$ is produced though neutron capture by ${ }^{235} \mathrm{U}$. In a natural ore or mineral, neutrons are produced from the spontaneous fission of ${ }^{238} U$ and ${ }^{235} U$, neutron fission of ${ }^{235} U$, and $(\alpha, n)$ reactions with lighter elements in the mineral matrix. The relative importance of these processes for neutron production were discussed by Seaborg and others more than 50 years ago during the quantitation of naturally occurring ${ }^{239} \mathrm{Pu}$ and ${ }^{237} \mathrm{~Np}[18-27]$. These early papers did not discuss the ${ }^{236} \mathrm{U}$ natural abundance, but only mentioned ${ }^{236} \mathrm{U}$ production as a sink for neutrons, limiting natural production of ${ }^{239} \mathrm{Pu}$. Natural ${ }^{236} \mathrm{U} /{ }^{238} \mathrm{U}$ ratios on the order of $10^{-10}$ have been reported in a variety of uranium containing ores and minerals $[9,10,12,28-30]$, but no widespread survey has been completed to date because levels are too low for routine detection by techniques other than AMS. These studies indicate that if the ${ }^{236} \mathrm{U} /{ }^{238} \mathrm{U}$ ratio is greater than $10^{-9}\left({ }^{236} \mathrm{U} /{ }^{234} \mathrm{U}>2 \times 10^{-5}\right)$, the sample has seen a significant neutron flux. 
The early papers discussing Pu production in natural materials also addressed the role of ${ }^{232} \mathrm{Th}$ in scavenging neutrons in some ores and minerals. The consequence of neutron capture by ${ }^{232} \mathrm{Th}$ is production of ${ }^{233} \mathrm{U}$ through the reaction chain ${ }^{232} \mathrm{Th}(\mathrm{n}, \gamma){ }^{233} \mathrm{Th} \rightarrow{ }^{233} \mathrm{~Pa}$ $\rightarrow{ }^{233} \mathrm{U}$. The other natural production chain for ${ }^{233} \mathrm{U}$ is ${ }^{238} \mathrm{U}(\mathrm{n}, 2 \mathrm{n}){ }^{237} \mathrm{U} \rightarrow{ }^{237} \mathrm{~Np} \rightarrow{ }^{233} \mathrm{~Pa}$ $\rightarrow{ }^{233} U$. Determination of the naturally occurring parent of the $(4 n+1)$ uranium series motivated the search for naturally occurring ${ }^{237} \mathrm{~Np}$ [19-23]. Small quantities of ${ }^{237} \mathrm{~Np}$ were measured $[20,21,23]$, but the dominant production path for ${ }^{233} \mathrm{U}$ is likely to be through neutron capture by ${ }^{232} \mathrm{Th}$. The natural concentration of ${ }^{233} \mathrm{U} /{ }^{238} \mathrm{U}$ in ores is estimated to be $10^{-11}-10^{-15}$ and no systematic survey has been conducted. The large variation in concentration of ${ }^{233} \mathrm{U}$ is due to variable concentrations of Th and competing neutron absorbers in ores and minerals.

We employed MC-ICPMS and AMS to conduct measurements of major and minor uranium isotopes in set of environmental samples. Table 1 lists the natural concentrations of uranium isotopes and the analytical methods used to measure them at LLNL. Both techniques measured ${ }^{234} \mathrm{U}$ and ${ }^{236} \mathrm{U}$. AMS used a ${ }^{233} \mathrm{U}$ spike for normalization of and the samples were not measured for intrinsic ${ }^{233} \mathrm{U}$ or ${ }^{232} \mathrm{U}$ content.

\subsection{Experimental}

\subsection{ICP-MS}

The isotopic analyses of uranium by multi-collector inductively coupled plasma mass spectrometry (MC-ICPMS) were made with an IsoProbe (GV Instruments) using a static multi-collection method. Samples were dissolved in $2 \% \mathrm{HNO}_{3}$ and introduced into the plasma with a Cetac Aridus ${ }^{\circledR}$ system. Operating at an uptake rate of 60 microliters per 
minute, ${ }^{238} \mathrm{U}$ beams of greater than $4 \times 10^{-12}$ amps were commonly obtained for a $1 \mathrm{ppb}$ natural uranium solution, which translates to a total efficiency (ions detected/atoms consumed) of about $1 \% .{ }^{236} \mathrm{U}$ was measured using the Daly detector pulse-counting system, while the ion currents from ${ }^{235} \mathrm{U}$ and ${ }^{238} \mathrm{U}$ were measured simultaneously on Faraday cup detectors. The efficiency of the pulse-counting system with respect to the Faraday cup detectors was determined by measuring ${ }^{234} \mathrm{U}$ on the Daly detector for a natural uranium standard with known ${ }^{234} \mathrm{U} /{ }^{235} \mathrm{U}$. This standard is NIST SRM 4321C, which derives from NBS SRM 960 = NBL CRM-112A (as does the NBL CRM 145 uranium normal solution). The ${ }^{238} \mathrm{U} /{ }^{235} \mathrm{U}$ of natural uranium is assumed to be 137.88 and the instrumental mass bias for uranium is calculated from the measured ratio on the Faraday detectors. After subtraction of the blank signal on the Daly detector at mass 234, which is determined on a pure $2 \% \mathrm{HNO}_{3}$ solution, the ${ }^{234} \mathrm{U} /{ }^{235} \mathrm{U}$ is corrected for instrumental mass bias using an exponential correction factor derived from Equation A4 in Russell et al. (1978) [31]. The exponent is determined from ${ }^{238} \mathrm{U} /{ }^{235} \mathrm{U}$ analyses of a uranium standard of known isotopic composition that bracket the sample analyses. Comparison of this blank-and-mass-bias-corrected ratio with the standard value gives the relative Daly/Faraday gain factor, which is found to be constant to within $0.3 \%$ (total range) for an analytical session. The measured ${ }^{236} \mathrm{U}$ ion currents on the Daly detector are corrected for blank, mass bias and Daly/Faraday gain. No correction is made for ${ }^{235} \mathrm{U}-{ }^{1} \mathrm{H}$ because uranium hydride occurs at less than 1 ppm (i.e., ${ }^{235} \mathrm{UH}^{+} /{ }^{235} \mathrm{U}^{+}<1 \times 10^{-6}$ ), as measured at mass 239 with respect to ${ }^{238} \mathrm{U}$. However, isobaric interferences at 10 's to 100 's of counts-per-second are seen on the IsoProbe at all masses in the actinide region, and this background at mass 236 results in an abundance sensitivity limit for ${ }^{236} \mathrm{U} /{ }^{235} \mathrm{U}$ of 
approximately $2 \times 10^{-6}$. The external precision on ${ }^{236} \mathrm{U} /{ }^{235} \mathrm{U}$ ratios is $0.3 \%$ (2-std. dev. of the population), as measured on NBS U010 isotopic standard. The mean value for ${ }^{236} \mathrm{U} /{ }^{235} \mathrm{U}$ obtained for replicate analyses of this standard is within $0.02 \%$ of the new NBL value measured by Richter and Goldberg (2001) [32].

\subsection{AMS}

Uranium samples were converted to a manageable amount of solid for use in the AMS ion source. In the case of environmental samples, the uranium is solubilized by acid digestion, separated, and purified, following standard procedures common to other techniques such as alpha spectrometry. The purified solution containing $400 \mathrm{ng} \mathrm{U}$ was taken to dryness, the uranium redissolved in $10 \mathrm{~mL}$ of $3 \mathrm{M} \mathrm{HNO}_{3}$, and coprecipitated with $0.3 \mathrm{mg}$ of $\mathrm{Fe}(\mathrm{III})$ by adding a 1:1 solution of $\mathrm{NH}_{4} \mathrm{OH}$. The precipitate was centrifuged, washed, and transferred to a $\sim 1-\mathrm{mL}$ capacity quartz crucible where it was taken to dryness. The solid in the crucible was subsequently heated to $800^{\circ} \mathrm{C}$ in a muffle furnace to convert it to the oxide form. Once cool, $3 \mathrm{mg}$ of niobium metal was added to the crucible and mixed with the oxide. The solid, comprised mostly of $\mathrm{Fe}_{2} \mathrm{O}_{3}$ and $\mathrm{Nb}$, was scraped from the crucible and loaded in an aluminum target holder. Blanks and standards were prepared in the same manner to turn them into solid form. For routine measurements of ${ }^{236} \mathrm{U}$, pure ${ }^{233} \mathrm{U}$ spike was added as a reference tracer. For measurements of ${ }^{233} \mathrm{U}, \mathrm{a}{ }^{236} \mathrm{U}$ spike is added as a reference. Typical samples contain $50-$ $500 \mathrm{ng} \mathrm{U}$ with $3 \times 10^{9}$ atoms of the reference spike. 
A description of the AMS system for heavy element analysis can be found in the literature $[13,33]$. In automatic operation, the system measures up to 5 different isotopes consecutively. Electrostatic deflector plates after the $30^{\circ}$ mass-analyzing magnet were used in combination with the fast mass switching capability of the low-energy spectrometer for isotope mass selection and fast normalization, i.e., fast switching between an isotope of interest and the reference isotope with measurement time intervals of hundreds of milliseconds. This improves the accuracy and precision of the measured ratios because the ion source output remains essentially constant between the short sampling intervals.

During each isotope measurement cycle, the system alternates between an isotope of interest and the reference isotope using sampling intervals of 400 and $100 \mathrm{msec}$, respectively. The measurement time per isotope was normally 10 seconds and the set of up to 5 isotopes was repeated 3 times per cycle for 15 total measurements per cycle. This measurement cycle was repeated 6-8 times for each sample. One of the 5 isotopes is routinely selected to be the reference isotope. This reference/reference measurement should yield a ratio of 1 and is used to normalize the data for any differences between the two acquisition channels (electronics, manual gates, etc.). The high-energy spectrometer was set to select the $5+$ charge state $\left(E_{\text {kinetic }}=39 \mathrm{MeV}\right)$ for detection. The signals from the detector were used to set a charge gate to count the 5+ events only, using an interactive two-dimensional plot of the energy signal of one anode of the detector versus the other. This gate was sufficient to reject neighboring $4+$ and lower charge-state ions that make it to the detector due to scattering in the high energy ESA. 
The ${ }^{236} \mathrm{U} /{ }^{233} \mathrm{U}$ control standards and "blank" samples were prepared using standard stock solutions. The solutions were prepared from a natural uranium standard (NBL CRM 112A), $\mathrm{a}^{236} \mathrm{U}$ standard (IPL 7336) and a ${ }^{233} \mathrm{U}$ standard (IPL 7233). A ${ }^{233} \mathrm{U}$ spike of $3 \times 10^{9}$ atoms was added to all samples for normalization. The quantity of ${ }^{236} \mathrm{U}$ included for construction of a calibration curve varied between $10^{6}$ and $10^{8}$ atoms. The calibration generated during the measurements of this sample set is depicted in Fig. 1. The average of six sample blanks was $2.2 \times 10^{6}$ atoms of ${ }^{236} \mathrm{U}$, significantly higher than our typical level of $\sim 5 \times 10^{5}{ }^{236} \mathrm{U}$ atoms [13]. The sample set was co-processed with samples containing $10^{11}$ atoms of ${ }^{236} \mathrm{U}$, which adversely skewed the blanks.

\subsection{Results \& Discussion}

\subsection{Major Uranium Isotopes}

Analysis of major uranium isotopes in these environmental samples by MC-ICPMS produced ratios similar to natural uranium (Table 2). The isotopic ratios varied slightly from the accepted natural levels, but were not significantly enriched or depleted. The variation of $\mathrm{U}$ isotopes reported in natural deposits $[28,34-37]$ is narrower than the range measured in our samples. Since the samples were acquired from a variety of sources, anthropogenic activities may have skewed the natural isotopic abundances from those found in ores and minerals.

\section{$3.2{ }^{236} U$ Measurements}

Samples were analyzed for ${ }^{234} \mathrm{U}$ and ${ }^{236} \mathrm{U}$ content by both MC-ICPMS and AMS. Both techniques report concentrations in terms of ratios to a different U isotope. MC-ICPMS 
measures ${ }^{234} U$ and ${ }^{236} U$ with respect to ${ }^{235} U$ and AMS measures them with respect to the counts from a ${ }^{233} \mathrm{U}$ spike of $3 \times 10^{9}$ atoms. The techniques can be compared using the ${ }^{236} \mathrm{U} /{ }^{234} \mathrm{U}$ ratio. Table 3 lists the ${ }^{236} \mathrm{U} /{ }^{234} \mathrm{U}$ ratio for samples A-M and the ${ }^{236} \mathrm{U} /{ }^{234} \mathrm{U}$ ratio of $1.82 \times 10^{-6}$ assuming a natural ${ }^{236} \mathrm{U} / \mathrm{U}$ concentration on the higher end of its natural range in ores of $10^{-10}$ The uncertainty in the AMS ratio is calculated from the square root of the sum of the squares of the relative uncertainties in number of ${ }^{236} \mathrm{U}$ and ${ }^{234} \mathrm{U}$ atoms counted. The relative uncertainty in the ${ }^{236} \mathrm{U}$ measurement is always the dominant term. The uncertainty in the MC-ICPMS ratio was calculated in a similar manner based on the ${ }^{234} \mathrm{U} /{ }^{235} \mathrm{U}$ and ${ }^{236} \mathrm{U} /{ }^{235} \mathrm{U}$ ratios. Again, the ${ }^{236} \mathrm{U}$ measurement drives the uncertainty since it is less precise due to its lower concentration.

Several of the environmental samples contained elevated levels of ${ }^{236} \mathrm{U}$, indicating the sample had been exposed to neutrons in the past or had been contaminated with reprocessed uranium. Analysis of the samples for other neutron capture products, as was done in the search for natural ${ }^{239} \mathrm{Pu}$ and ${ }^{237} \mathrm{~Np}$ [19-24], might confirm which scenario is correct. Failure to detect other neutron capture products does not rule out exposure to an anthropogenic neutron source, however, since elements are transported differently in the environment depending on chemical form.

The main limit of quantification for minor or trace uranium isotopes is the abundance sensitivity of the measurement technique, i.e., the ability to measure a minor or low abundance isotope in the presence of a major isotope at $\mathrm{M} \pm 1$ mass units. The abundance sensitivity for ${ }^{236} \mathrm{U} /{ }^{235} \mathrm{U}$ isotope ratio measurements using MC-ICPMS is $\sim 2 \times 10^{-6}$. This compares with a ${ }^{236} \mathrm{U} /{ }^{235} \mathrm{U}$ abundance sensitivity of $\sim 1 \times 10^{-7}$ for the AMS system as 
configured during these measurements. The recent addition of a new low energy injection magnet with a large pole gap has improved transmission efficiency on the AMS system but has not significantly changed the abundance sensitivity.

The major outcome of this study is the agreement between MC-ICPMS and AMS results for the samples that contained levels of ${ }^{236} U$ measurable by both methods (Fig. 2). The uncertainties depicted in Fig. 2 are as described above for Table 3. These uncertainties are associated with counting statistics and the inherent uncertainties of the standards. In most cases, ${ }^{236} \mathrm{U} /{ }^{234} \mathrm{U}$ measurements by AMS produced lower values than MC-ICPMS. Checks of the ${ }^{233} \mathrm{U}$ concentrations of the reference spike solutions confirmed the magnitudes of the spikes. Differences in sample processing between the independent MS techniques may be responsible for the variability observed. To our knowledge, this study is the first to demonstrate a strictly linear correspondence between MC-ICPMS and AMS for $U$ isotopes. Neither MS method employed could reach the "natural ore" ${ }^{236} U{ }^{234} U$ of $\sim 2 \times 10^{-6}$. Most of other AMS systems currently measuring ${ }^{236} \mathrm{U}$, as described at the AMS10 Meeting in September 2005, seem to have the same limits in quantitation. Hebrew University [13] and VERA [17] previously reported measuring ${ }^{236} \mathrm{U} / \mathrm{U}$ below $10^{-10}$ $\left.{ }^{236} \mathrm{U}^{234} \mathrm{U}<2 \times 10^{-6}\right)$. The VERA facility is also the only one with an additional high energy filter before the detector to remove rare scattered ions masquerading as ${ }^{236} U$ [17].

\subsection{Conclusions}

MC-ICPMS and AMS are complementary analysis methods with the ability to independently measure ${ }^{234} \mathrm{U}$ and ${ }^{236} \mathrm{U}$. AMS analysis independently confirms elevated

${ }^{236} \mathrm{U}$ measurements by MC-ICPMS. The current AMS system at LLNL lowers ${ }^{236} \mathrm{U}$ 
quantitation more than an order of magnitude below MC-ICPMS. Plans for adding an additional high energy filter to the AMS system are underway, which should drop our ${ }^{235} \mathrm{U}$ scattering background 2-3 orders of magnitude. We anticipate a capability for routine measurement of natural levels of ${ }^{236} \mathrm{U}$ and ${ }^{233} \mathrm{U}$ after this addition. Our current capability of measuring ${ }^{233} \mathrm{U}$ is actually better than ${ }^{236} \mathrm{U}$ due to chemical removal of the scattering M-1 isotope $\left({ }^{232} \mathrm{Th}\right)$ during sample processing. Several other natural neutron monitors are potentially present in some ores and minerals. Beyond the classics ${ }^{239} \mathrm{Pu}$ and ${ }^{237} \mathrm{~Np}$, several AMS facilities could assess ${ }^{41} \mathrm{Ca}$ and ${ }^{36} \mathrm{Cl}$ concentrations with current measurement capabilities.

\section{Acknowledgement}

This work was performed under the auspices of the U.S. Department of Energy by University of California, Lawrence Livermore National Laboratory under Contract W7405-Eng-48. 


\section{References}

[1] A.O. Nier, E.T. Booth, J.R. Dunning and A.V. Grosse. Nuclear fission of separated uranium isotopes. Phys Rev 57(1940) 546.

[2] W.R. Shields. US Nat Bur Stds Meeting of the Advisory Committee, May 17-18, 1960. $37 \mathrm{pp}$.

[3] J.H. Chen and G.J Wasserburg. Isotopic determination of uranium in picomole and subpicomole quantities. Anal. Chem. 53 (1981) 2060.

[4] W. Kerl, J.S. Becker, H.-J. Dietze and W. Dannecker. Isotopic and Ultratrace Analysis of Uranium by Double-Focusing Sector Field ICP Mass Spectrometry. Fresenius J. Anal. Chem 359 (1997) 407.

[5] S. Richter and S. A. Goldberg. Improved techniques for high accuracy isotope ratio measurements of nuclear materials using thermal ionization mass spectrometry. Int. J Mass Spectrom. 229 (2003) 181.

[6] X.D. Hou, W. Chen, Y.H. He, And B.T. Jones. Analytical atomic spectrometry for nuclear forensics. Appl. Spectros. Rev., 40 (2005) 245.

[7] M. Suter. 25 years of AMS - a review of recent developments. Nucl. Instr. and Meth. B 223-224 (2004) 139.

[8] W. Kutschera. Progress in isotope analysis at ultra-trace level by AMS. Int. J. Mass Spectrom. 242 (2005) 145.

[9] X.-L. Zhao, M.-J. Nadeau, L.R. Kilius and A.E. Litherland. The First Detection of Naturally-Occurring ${ }^{236} \mathrm{U}$ with Accelerator Mass Spectrometry. Nucl Instr. And Meth. B 92 (1994) 249.

[10] O.J. Marsden, F.R. Livens, J.P. Day, L.K. Fifield, and P.S. Goodall Determination of U-236 in sediment samples by accelerator mass spectrometry. Analyst 126 (2001) 633.

[11] D. Berkovits, H. Feldstein, S. Ghelberg, A. Hershkowitz, E. Navon, and M. Paul. ${ }^{236} \mathrm{U}$ in uranium minerals and standards. Nul. Instr.and Meth.B 172 (2000) 372.

[12] P. Steier, R. Golser, W. Kutschera, V Liechtenstein, A. Priller, A. Valenta, C. Vockenhuber. Heavy ion AMS with a "small" accelerator. Nucl. Instr. \& Meth. B, 188, (2002) 283.

[13] T.A. Brown, A.A. Marchetti, R.E. Martinelli, C.C. Cox, J.P. Knezovich, and T.F. Hamilton. Actinide measurements by accelerator mass spectrometry at Lawrence Livermore National Laboratory. Nucl. Instr. and Meth. B 223-224 (2004) 788. 
[14] D.P. Child, M.A.C Hotchkis, and M.L. Williams. Improvements in Actinide and Fission Product Analysis by AMS - Raising the Bar and Lowering Detection Limits in Heavy Element Analyis. Proceedings of the 46th Annual Meeting of the Institute for Nuclear Materials Management. July 10-14, 2005 Phoenix, Arizona USA.

[15] K.M. Wilcken, T.T. Barrows, L.K. Fifield, S.G. Tims and P. Steier. AMS of Natural U-236 and Pu-239 Produced in Uranium Ores. Nucl. Instr. and Meth. B these Proceedings (2006).

[16] L. Wacker, E. Chamizo, L. K. Fifield, M. Stocker, M. Suter, and H. A. Synal. Measurement of actinides ona compact AMS system working at $300 \mathrm{kV}$. Nucl. Instr. and Meth. B 240 (2005) 452.

[17] C. Vockenhuber, I. Ahmad, R. Golser, W. Kutschera, V. Liechtenstein, A. Priller, P. Steier, S. Winkler. Accelerator mass spectrometry of heavy long-lived radionuclides. Int. J. Mass Spectrom. 223 (2003) 713.

[18] W.F. Libby. Stability of Uranium and Thorium for Natural Fission. Phys. Rev. 55 (1939) 1269.

[19] G.T. Seaborg, A.C. Wahl. The Chemical Properties of Elements 94 and 93. J. Am. Chem. Soc. 70 (1948) 1128.

[20] G.T. Seaborg and M.T. Perlman. Search for Elements 94 and 93 in Nature. Presence of $94^{239}$ in Pitchblend. J. Am. Chem. Soc. 70 (1948) 1571.

[21] C. S. Garner, N. A. Bonner, G. T. Seaborg. Search for Elements 94 and 93 in Nature. Presence of $94^{239}$ in Carnotite. J. Am. Chem. Soc. 70 (1948) 3453.

[22] C.A. Levine and G. T. Seaborg. The Occurrence of Plutonium in Nature. J. Am. Chem. Soc. 73 (1951) 3278.

[23] D.F. Peppard, M.H. Studier, M.V. Gergel, G.W. Mason, J.C. Sullivan and J.F. Mech. Isolation of Microgram Quantities of Naturally-occurring Plutonium and Examination of its Isotopic Composition. J. Am. Chem. Soc. 73 (1951) 2529.

[24] D.F. Peppard, G.W. Mason, P.R. Gray and J.F. Mech. Occurrence of the $(4 n+1)$ Series in Nature. J. Am. Chem. Soc. 74 (1952) 6081.

[25] E. Segre. Spontaneous Fission. Phys. Rev. 86 (1952) 21.

[26] D.J. Littler. A determination of the Rate of Emission of Spontaneous Fission Neutrons by Natural Uranium. Proc. Phys. Soc. A 65 (1952) 203.

[27] W.H. Fleming and H.G. Thode. Neutron and Spontaneous Fission in Uranium Ores. Phys.Rev. 92 (1953) 378. 
[28] S. Richter, A. Alonso, W. De Bolle, R. Wellum, P.D.P. Taylor. Isotopic "fingerprints" for natural uranium ore samples. Int. J. Mass Spectrom. 193(1999) 9.

[29] D.J. Rokop, D.N. Metta and C.M. Stevens. 236U/238U Measurements in Three Terrestrial Minerals and One Processed Ore. Int. J. Mass Spectrom. Ion Phys. 8 (1972) 259.

[30] S. Kraft, V. Andrianov, A. Bleile, P. Egelhof, R. Golser, A. Kiseleva, O. Kiselev, W. Kutschera, J. P. Meier, A. Priller, A. Shrivastava, P. Steier, and C. Vockenhuber, First application of calorimetric low-temperature detectors in accelerator mass spectrometry. Nucl. Instrum. and Meth. A 520 (2004) 63.

[31] W. A. Russell, D. A. Papanastassiou, T. A. Tombrello, Ca isotope fractionation on the Earth and other solar system materials. Geochem. Cosmochim. Acta 42, (1978) 1075.

[32] S. Richter and S. A. Goldberg (2001) Progress in Precision and Accuracy for Isotope Ratio Measurements of Nuclear Samples using Thermal Ionization Mass Spectrometry, $42^{\text {nd }}$ INMM Annual Meeting, Indian Wells, California, July 15-19, 2001.

[33] A. A. Marchetti, T. A. Brown, C. C. Cox, T. F. Hamilton, and R. E. Martinelli. Accelerator mass spectrometry of actinides. J. Radioanal.Nucl. Chem. 263 (2005) 483.

[34] M. Lounsbury. The Natural Abundances of Uranium Isotopes. Can. J. Phys. 34 (1956) 259.

[35] A.N. Hamer and E.J. Robbins. Search for Variations in the Natural Abundance of Uranium-235. Geochim. Cosmochim. Acta 19 (1960) 143.

[36] G.A. Cowan and H.H. Adler. The Variability of the Natural Abundance of ${ }^{235}$ U. Geochim. Cosmochim. Acta 40 (1976) 1487.

[37] J.K. Böhlke, J.R. de Laeter, P. De Bièvre, H. Hidaka, H.S. Peiser, K.J.R. Rosman, P.D.P. Taylor. Isotopic compositions of the elements, 2001. J. Phys. Chem. Ref. Data 34 (2005) 57. 
Table 1. Natural Abundances of Uranium Isotopes and Measurement Technique Used to Quantify them. Isotopes are described as major, minor or trace. ${ }^{232} \mathrm{U}$ is currently measured by $\alpha$-spectroscopy due to its short half-life and mass interference with ${ }^{232} \mathrm{Th}$.

\begin{tabular}{|l|l|l|l|}
\hline Isotope & $\begin{array}{l}\text { Natural U } \\
\text { concentration }(\%)\end{array}$ & MC-ICPMS & AMS \\
\hline${ }^{238} \mathrm{U}$ & 99.2745 & major & \\
\hline${ }^{236} \mathrm{U}$ & $10^{-10}-10^{-8}$ & minor & minor \\
\hline${ }^{235} \mathrm{U}$ & 0.720 & major & \\
\hline${ }^{234} \mathrm{U}$ & 0.0055 & minor & minor \\
\hline${ }^{233} \mathrm{U}$ & $10^{-13}-10^{-9}$ & & trace \\
\hline
\end{tabular}

Table 2. Major uranium isotope concentrations measured by MC-ICPMS.

\begin{tabular}{|c|c|c|c|c|}
\hline Sample & $238 / 235$ & $\pm 2 \sigma$ & $234 / 235$ & $\pm 2 \sigma$ \\
\hline $\mathbf{A}$ & 137.77 & 0.07 & $7.565 \mathrm{E}-03$ & $3.5 \mathrm{E}-05$ \\
\hline B & 137.80 & 0.07 & $7.558 \mathrm{E}-03$ & $3.5 \mathrm{E}-05$ \\
\hline $\mathbf{C}$ & 137.98 & 0.06 & $7.581 \mathrm{E}-03$ & $3.2 \mathrm{E}-05$ \\
\hline D & 137.92 & 0.06 & 7.572E-03 & $3.2 \mathrm{E}-05$ \\
\hline $\mathbf{E}$ & 137.15 & 0.09 & 7.603E-03 & $3.6 \mathrm{E}-05$ \\
\hline $\mathbf{F}$ & 137.65 & 0.24 & $7.539 \mathrm{E}-03$ & $4.1 \mathrm{E}-05$ \\
\hline $\mathbf{G}$ & 137.90 & 0.12 & 7.578E-03 & 4.3E-05 \\
\hline $\mathbf{H}$ & 137.85 & 0.11 & $7.556 \mathrm{E}-03$ & $3.6 \mathrm{E}-05$ \\
\hline I & 136.84 & 0.25 & $7.636 \mathrm{E}-03$ & 4.7E-05 \\
\hline $\mathbf{J}$ & 137.45 & 0.12 & $7.587 \mathrm{E}-03$ & 4.1E-05 \\
\hline $\mathbf{K}$ & 137.70 & 0.25 & $7.507 \mathrm{E}-03$ & $4.5 \mathrm{E}-05$ \\
\hline $\mathbf{L}$ & 137.65 & 0.24 & 7.539E-03 & 4.1E-05 \\
\hline M & 137.45 & 0.12 & $7.587 \mathrm{E}-03$ & 4.1E-05 \\
\hline Nat $U$ & 137.88 & & $7.639 \mathrm{E}-03$ & \\
\hline
\end{tabular}


Table $3 .{ }^{236} \mathrm{U} /{ }^{234} \mathrm{U}$ ratio measured by MC-ICPMS and AMS.

\begin{tabular}{|c|c|c|c|c|}
\hline \multirow{2}{*}{ RSample } & \multicolumn{2}{|c|}{ ICPMS } & \multicolumn{2}{c|}{ AMS } \\
\cline { 2 - 5 } & ${ }^{236} \mathrm{U} /{ }^{234} \mathrm{U}$ & $\pm 2 \sigma$ & ${ }^{236} \mathrm{U} /{ }^{234} \mathrm{U}$ & $\pm 2 \sigma$ \\
\hline $\mathrm{A}$ & $2.38 \mathrm{E}-03$ & $2.91 \mathrm{E}-04$ & $2.89 \mathrm{E}-03$ & $3.03 \mathrm{E}-04$ \\
\hline B & $<2.65 \mathrm{E}-04$ & & $<8.00 \mathrm{E}-05$ & \\
\hline C & $<2.64 \mathrm{E}-04$ & & $<8.20 \mathrm{E}-05$ & \\
\hline$D$ & $<2.64 \mathrm{E}-04$ & & $<9.23 \mathrm{E}-05$ & \\
\hline E & $1.74 \mathrm{E}-02$ & $1.06 \mathrm{E}-03$ & $1.26 \mathrm{E}-02$ & $8.62 \mathrm{E}-04$ \\
\hline F & $<3.7 \mathrm{E}-03$ & & $<8.81 \mathrm{E}-05$ & \\
\hline G & $1.25 \mathrm{E}-02$ & $1.32 \mathrm{E}-03$ & $9.22 \mathrm{E}-03$ & $6.28 \mathrm{E}-04$ \\
\hline H & $<3.7 \mathrm{E}-03$ & & $6.10 \mathrm{E}-03$ & $4.99 \mathrm{E}-04$ \\
\hline I & $2.80 \mathrm{E}-02$ & $1.58 \mathrm{E}-03$ & $2.42 \mathrm{E}-02$ & $1.97 \mathrm{E}-03$ \\
\hline J & $2.29 \mathrm{E}-02$ & $1.32 \mathrm{E}-03$ & $1.85 \mathrm{E}-02$ & $1.37 \mathrm{E}-03$ \\
\hline K & $<3.7 \mathrm{E}-03$ & & $1.21 \mathrm{E}-04$ & $6.07 \mathrm{E}-05$ \\
\hline L & $<3.7 \mathrm{E}-03$ & & $<8.76 \mathrm{E}-05$ & \\
\hline M & $2.29 \mathrm{E}-02$ & $1.32 \mathrm{E}-03$ & $1.82 \mathrm{E}-02$ & $2.32 \mathrm{E}-03$ \\
\hline Nat U & $1.82 \mathrm{E}-06$ & & $1.82 \mathrm{E}-06$ & \\
\hline
\end{tabular}




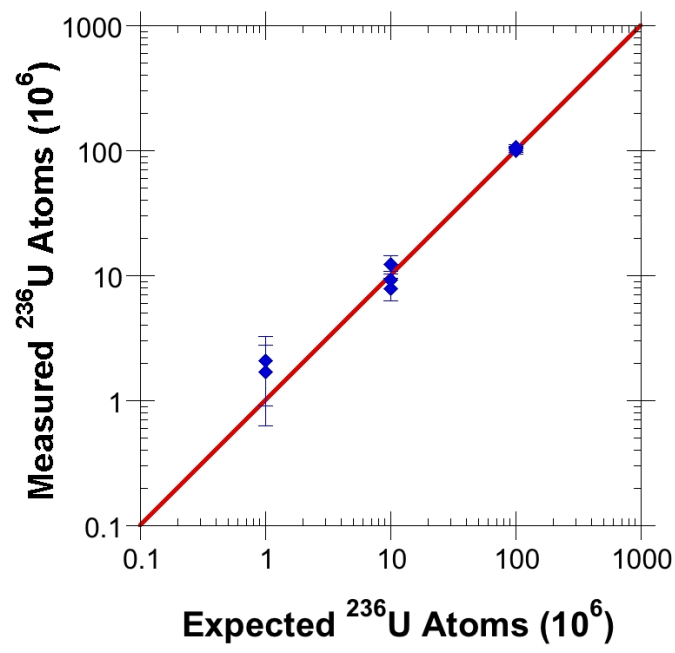

Fig. 1. Calibration curve for $\mathrm{AMS}{ }^{236} \mathrm{U}$ measurements. 


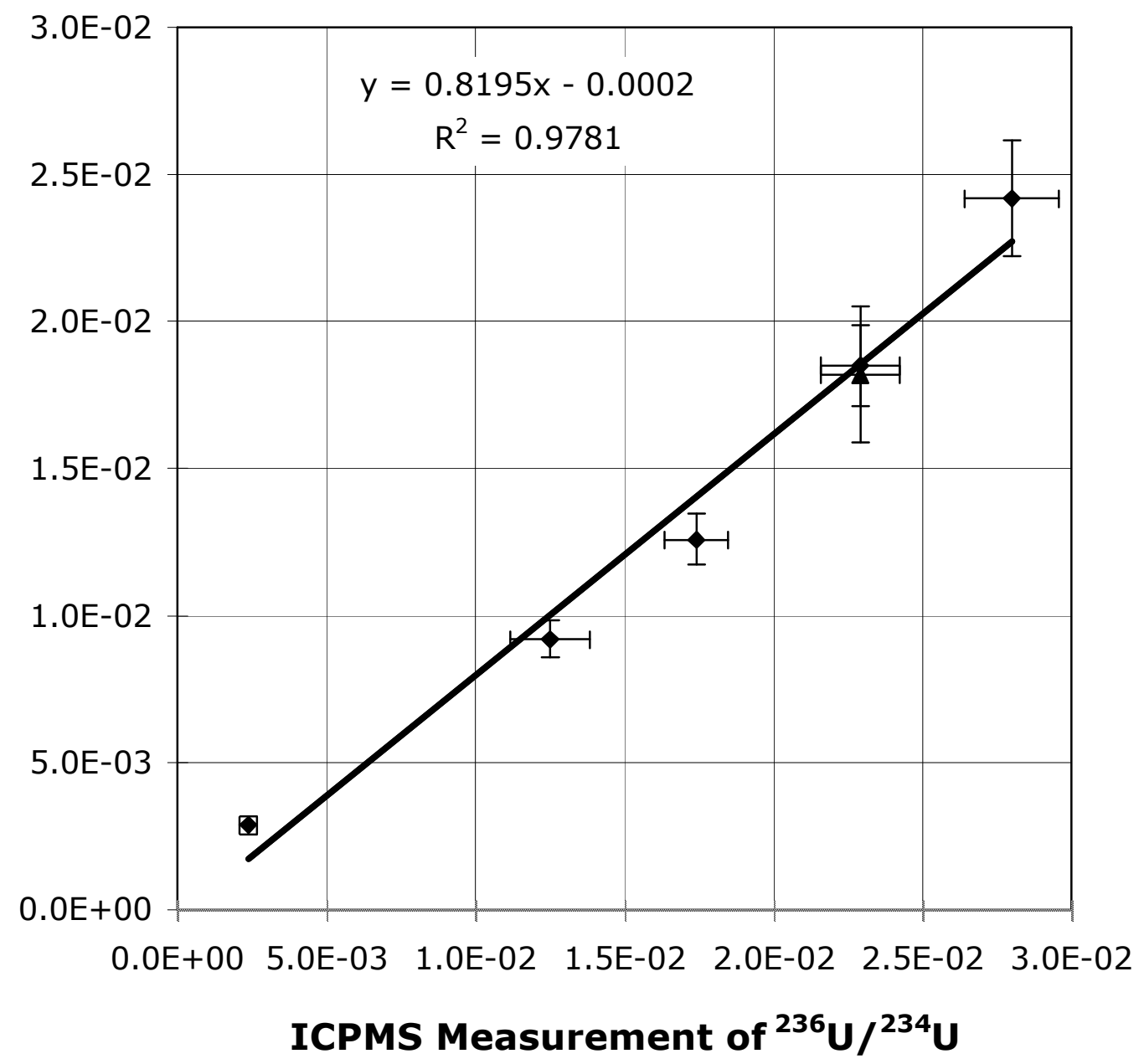

Fig. 2 Regression analysis comparison of ${ }^{236} \mathrm{U} /{ }^{234} \mathrm{U}$ measured by MC-ICPMS and AMS. 